\title{
Tecnologias da tradução e a pedagogia colaborativa
}

\section{Translation technologies and collaborative pedagogy}

\section{Marileide Dias Esqueda*}

Resumo: Partindo do pressuposto de que uma tradução é o resultado da influência de vários "colaboradores" que dela participam direta ou indiretamente, tais como clientes, tradutores, terminólogos, revisores, público-alvo, dentre outros, este trabalho descreve possibilidades para a adoção da pedagogia colaborativa na formação de tradutores, viabilizada pelo uso de ferramentas específicas presentes em sistemas de memória de tradução.

Palavras-chave: Ensino de tradução; Formação de tradutores; Pedagogia colaborativa; Sistemas de memória de tradução.

Abstract: Based on the assumption that a translation is the result of the influence of several "collaborators" who directly or indirectly take part in it, such as clients, translators, terminologists, reviewers, target readers, among others, this paper describes possibilities for the incorporation of a collaborative pedagogy in the translator education through specific features belonging to translation memory systems.

Keywords: Translation teaching; Translator training; Collaborative pedagogy; Translation memory systems.

\footnotetext{
* Professora Associada do Programa de Pós-Graduação em Estudos Linguísticos e do Curso de Bacharelado em Tradução do Instituto de Letras e Linguística da Universidade Federal de Uberlândia. E-mail: marileide.esqueda@ufu.br
} 


\title{
1. Tradução colaborativa e pedagogia colaborativa: algumas definições
}

\author{
Para Cordingley e Manning (2017), a imagem popular do tradutor \\ solitário está em desacordo com a realidade de seu trabalho dentro da \\ profissão. Seja em contexto literário ou técnico, muitos "colaboradores", com \\ diferentes papéis, normalmente moldam um texto traduzido antes de publicá- \\ lo. Para os autores, mesmo que se defina a tradução de forma restritiva, \\ limitando-a a decodificar um texto-fonte e escrevê-lo em outro idioma, essa \\ prática, ao longo da história, nem sempre foi considerada uma atividade \\ solitária:
}

Da Antiguidade ao Renascimento, a tradução era praticada com frequência por grupos compostos de especialistas de diferentes línguas e com habilidades variadas. No centro das equipes de tradução, especialistas de várias culturas se reuniam para encontrar soluções para os problemas de tradução (...). (CORDINGLEY; MANNING 2017: 1 , tradução nossa. $)^{1}$

Nos dias de hoje, a tradução colaborativa, na qualidade de um hiperônimo, traz consigo a ideia de práticas específicas de tradução, relacionadas à tradução coletiva (crowdsourcing translation)², tradução voluntária (volunteer translation), tradução comunitária (community translation), tradução participativa (participative translation), dentre outros termos correlatos, tais como tradução colaborativa em rede (on-line

\footnotetext{
1 From Antiquity to the Renaissance, translation was frequently practised by groups comprised of specialists of different languages and with varied skills. At the centre of translation teams, experts from various cultures came together to find solutions to translation problems (...).

2 Para Jiménez-Crespo (2017), crowdsourcing in translation refere-se à prática pela qual as traduções são produzidas por grupos de usuários voluntários através da internet, formando uma comunidade on-line. 0 autor argumenta que tal prática surgiu a partir da natureza participativa da Web 2.0 e da crescente inserção da internet em todo o mundo, em consonância com a crença de seu criador, Tim Berners-Lee, de que a web é uma criação social. O termo crowdsourcing refere-se à junção das palavras "multidão" e "terceirização", sendo definido como o ato de terceirizar, a um grupo indefinido de pessoas, e na forma de uma chamada aberta, um trabalho (neste caso, uma tradução) que era tradicionalmente executado por um único agente (tradutor). Jiménez-Crespo (2017: 194) ainda explica que a característica mais importante da prática de crowdsourcing é sua dependência de ambientes colaborativos mediados pela web. As chamadas abertas podem ser iniciadas por empresas ou instituições, bem como por comunidades de tradução auto-organizadas.
} 
collaborative translation ou on-line volunteer collaborative translation). Para Pym (2011), Cordingley e Manning (2017), Cronin (2017) e Jiménez-Crespo (2017) ainda perdura uma instabilidade definitória envolvendo a tradução colaborativa, cujos efeitos estão relacionados à autoria, identidade, criatividade, remuneração, ao reconhecimento do trabalho de tradutores profissionais, às práticas ativistas, apenas para mencionar alguns. Ao discutirem tais efeitos, esses autores afirmam que, sob a retórica positiva do "compartilhamento", o modelo de tradução colaborativa tem sido utilizado por algumas corporações gigantes, que vêm operando em regimes fiscais mínimos e acabam por solapar a profissão de tradutor.

À parte essas tão necessárias e urgentes discussões implementadas pelos autores citados, e por outros que analisam, ao longo da história, os novos modelos tradutórios e seus impactos para a profissão (CHESTERMAN 2007; WOLF; FUKARI 2007; MCDONOUGH DolmaYa 2011), este artigo não se envereda pelas esferas ético-profissionais e históricas das práticas colaborativas, sejam elas implementadas por empresas ou pelos membros de uma determinada comunidade, mas se interessa pela temática no que concerne ao fluxo de trabalho e interação entre os agentes que delas participam, principalmente por meio do vetor contemporâneo das novas tecnologias e da internet e de suas relações com a formação de tradutores.

Partindo do pressuposto de que a tradução inevitavelmente possui níveis de colaboração entre seus agentes, formando um continuum colaborativo que envolve o cliente, o tradutor, o terminólogo, o revisor e o leitor em prospecção, que direta ou indiretamente exercem influência no texto a ser traduzido, o ensino de tradução também poderá aglutinar proposições didáticas colaborativas que venham a promover, dinamicamente, a troca de experiências entre professores, alunos e outros colaboradores ou agentes, espelhando o denominado continuum colaborativo e, ainda, não privando os tradutores em formação do conhecimento acerca dessas possíveis práticas e dos aparatos tecnológicos a elas relacionados.

Para Kiraly (1995, 2000, 2014) e González-Davies (2017), adotar a pedagogia colaborativa na sala de aula de ensino de tradução é uma forma eficaz de estimular os alunos ao pensamento crítico e às formas de solucionar 
problemas do mundo real. Além disso, tal pedagogia promove a melhor compreensão do processo tradutório e resulta em um avanço na competência atitudinal dos alunos, capacitando-os a lidar com as incertezas dos textos e a tomar decisões conjuntas mais responsáveis e informadas.

O pensamento socioconstrutivista, no qual estão pautadas as experiências colaborativas de sala de aula, abandona a abordagem centrada no professor e visa a autonomia dos aprendizes, isto é, a centralidade do papel dos alunos na tomada de decisão e na produção de um texto válido e com potencial de publicação; a conscientização dos aprendizes, que pode ser alcançada por meio da reflexão, interação e acesso a recursos e materiais apropriados oferecidos por outros agentes envolvidos na produção das traduções; e a autenticidade da atividade, alcançada por meio de experiências reais ${ }^{3}$, que incluem projetos de tradução semelhantes àqueles encontrados na vida profissional, durante os quais são vivenciadas as imprevisibilidades dos contextos envolvidos. (KIRALY 1995, 2000, 2014; GONZÁLEZ-DAVIES 2017).

Nas palavras de Kiraly (2000),

A verdadeira colaboração em sala de aula não significa que os aprendizes traduzam individualmente na companhia de seus colegas. Significa compartilhar responsabilidades para o fortalecimento do grupo todo como profissionais emergentes. 0 processo de tomada de decisão se torna o segundo foco principal de atenção da classe, além dos artefatos desses processos. Para garantir uma verdadeira colaboração em sala de aula, os alunos devem ser mutuamente dependentes uns dos outros para alcançar seus objetivos. Na vida profissional, assim como em todas as iniciativas humanas, os tradutores devem estar capacitados a trabalhar cooperativamente uns com os outros. A interdependência promove e ensina sobre a responsabilidade, ao passo que 0 comprometimento individual garante que cada aluno contribua com os objetivos comuns do grupo, bem como adquira as habilidades sociais e de tradução necessárias para trabalhar profissionalmente ao mesmo tempo em que completam seus cursos. ${ }^{4}$ (KIRALY 2000: 67, tradução nossa)

\footnotetext{
3 Para Kiraly (2014), a autenticidade não se refere apenas à consecução de um exercício solicitado por um cliente real, mas também encena o imprevisível na sala de aula, que surge a partir das contribuições e necessidades reais dos alunos durante o processo de realização de uma tradução, o que o autor denomina como sendo um passo complementar à abordagem socioconstrutivista, rumo à aprendizagem emergente na era pós-positivista.

4 True collaboration in the classroom does not mean having learners do translations individually in the company of peers. It means sharing responsibility for empowering the entire group as emergent professionals. The process of decision-making becomes a second
} 
Na pedagogia colaborativa, os alunos irão, ao mesmo tempo, planejar, gerenciar, executar e tornar a tradução por eles realizada um material satisfatório a ser entregue para um cliente real. Nesse sentido, em vez de o professor elaborar as atividades que simulem as tarefas tradutórias, ou escolher os textos a serem traduzidos, os alunos, ao receberem a solicitação de uma tradução, advinda de um cliente real, serão os responsáveis pela identificação dos aspectos envolvidos em um projeto de tradução.

Para Pitkäsalo e Ketola (2018), no ensino e aprendizagem colaborativos, os alunos são divididos em pequenos grupos e a carga de trabalho geral é partilhada entre eles. Os grupos coordenam seus próprios deveres entre si, orientados pelo professor. Em outras palavras, os principais objetivos desse tipo de abordagem didática são, além de desenvolver habilidades de tradução em relação a um determinado tipo de texto e assunto, propiciar a formação em tradução por meio do gerenciamento de projetos, fortemente cerceados, nos dias atuais, pelas novas tecnologias, e capacitar ao trabalho em grupo. Nas palavras das autoras:

Os alunos têm que adotar diferentes papéis na tarefa de tradução, coordenar seu próprio projeto e gerenciar o tempo, bem como dos respectivos grupos. A execução depende, em grande parte, de os alunos assumirem a responsabilidade e adotarem um papel ativo no processo, transcendendo o ambiente tradicional de sala de aula em que os alunos meramente seguem as instruções dadas. (PITKÄSALO; KETOLA 2018: 95, tradução nossa) ${ }^{5}$

A partir do exposto, busca-se descrever, a seguir, como tornar a sala de aula de tradução um ambiente de trabalho no qual os alunos, orientados pelo professor, trabalham em conjunto, formando uma comunidade de prática

primary focus of attention in the class along with the artifacts of those processes. To ensure true collaboration in the classroom, students must be mutually dependent on each other for accomplishing goals. In their professional lives, as in most human endeavours, translators will have to be able to work co-operatively with each other. Interdependence fosters and teaches responsibility, while individual accountability ensures that each student is contributing to the common goals of the group as well as acquiring the necessary social and translational skills to work professionally upon completing the programme.

5 The students have to adopt different roles in the translation assignment and coordinate both their own project and time management, as well as those of their respective groups. The execution depends largely on the students taking responsibility and adopting an active role in the process, transcending the traditional classroom setting in which the students merely follow given instructions. 
(WENGER 1998)6 ${ }^{6}$, que compartilha responsabilidades durante o processo de aprendizagem, fazendo uso de um apropriado ferramental tecnológico.

Em outras palavras, este artigo configura-se como uma proposição didática, de viés teórico, especialmente embasado nos típicos problemas de pesquisa dos Estudos da Tradução, como os descritos por Williams e Chesterman (2002). Esses autores argumentam que as pesquisas desse campo disciplinar necessitam averiguar o impacto das novas tecnologias na formação de tradutores. Eles também destacam a importância de se questionar como os módulos concernentes às novas tecnologias poderiam incluir um estudo mais detalhado dos sistemas de memória de tradução, das ferramentas de localização, dentre outros, e como tais módulos deveriam ser trabalhados junto aos alunos, buscando-se lograr a formação de excelência (WiLLIAMs; Chesterman 2002: 26).

Com base nessa delimitação metodológica, objetiva-se descrever a organização de uma sequência de atividades que envolva os alunos em projetos autênticos e colaborativos de tradução, particularizando algumas das ferramentas e funcionalidades presentes em programas computacionais de auxílio à tradução, com ênfase especial aos sistemas de memória de tradução.

Não se trata de dar destaque às formas de compartilhamento tecnológico de memórias e glossários como aquelas disponibilizadas em sistemas de memória de tradução on- ou off-line, a partir dos quais os tradutores dão permissões a outros usuários para a troca de arquivos relativos às suas traduções. As atividades e as ferramentas tecnológicas que serão descritas a seguir visam à execução de um projeto colaborativo de tradução que, encomendado por um cliente real, incorpora à tarefa distintos agentes, como a figura do gerente de projetos, dos terminólogos, dos tradutores e dos revisores.

Assim, além desta introdução, descreve-se, na seção seguinte, o desenho geral da atividade didática, dando ênfase aos agentes que podem

\footnotetext{
${ }^{6}$ Para Wenger (1998), uma comunidade de prática é diferente de uma equipe de trabalho ou de trabalhos em grupos, pois seus membros desenvolvem entre si sua própria compreensão do que é a prática. Esse processo "vivo" resulta em uma definição muito mais rica do que a simples delimitação de objetivos a serem alcançados pelos grupos. Para o autor, uma comunidade de prática passa a existir quando produz uma prática compartilhada, em que seus membros se envolvem em um processo coletivo de aprendizagem. 0 termo comunidade de prática também é utilizado e discutido por González-Davies (2017).
} 
fazer parte de um projeto colaborativo de tradução. Na seção 2, expõem-se as principais ferramentas e funcionalidades dos sistemas de memória de tradução que são propícias à pedagogia colaborativa, tais como a criação de pacotes e de pacotes de retorno, as funcionalidades de um plug-in que serve à coleta da terminologia presente nos textos e, por fim, a acoplagem de outros textos que podem dar apoio à tarefa tradutória.

o propósito é demonstrar formas de inserção da pedagogia colaborativa viabilizada pelo uso de sistemas de memória de tradução que, atualmente, se tornaram ferramentas essenciais ao tradutor profissional e, por consequência, ao tradutor em formação (EsquedA; STUPIELlo 2016). Esse tipo de atividade pode ter caráter modular e leva em consideração a inserção de materiais e exercícios autênticos de tradução.

Por fim, na última seção, busca-se retomar o exposto e encaminhar novas frentes de investigação direcionadas à sala de aula de ensino de tradução.

Espera-se que professores e alunos se beneficiem desta proposição didática, principalmente devido à escassez de estudos que versem sobre o uso das tecnologias de tradução envolvendo projetos tradutórios mais duradouros e de enfoque colaborativo conduzidos aos contextos de ensino e aprendizagem. A proposição didática que ora se apresenta pode ser uma alternativa para se substituir o ensino transmissionista e demasiadamente centrado no professor (ESQUEDA 2018).

\section{A proposta geral de uma atividade didática que visa à colaboração}

Para fins de descrição de uma atividade didática que adota a abordagem colaborativa (KIRALY 2000), supõe-se que um grupo de aproximadamente 20 alunos tenha recebido a solicitação de traduzir um artigo científico de aproximadamente 30 páginas, por exemplo, do inglês para o português. 0 cliente pode ser um professor de uma área do conhecimento do mesmo cenário acadêmico ao qual pertencem os alunos, que utilizará o artigo, após traduzido, com um grupo de graduandos ou pós-graduandos que 
estudam o tema da publicação e que não possuem proficiência linguística em língua inglesa.

Esse professor, doravante denominado docente-cliente, poderá, durante a consecução do projeto, atuar como um consultor junto aos alunos, sanando dúvidas ou sugerindo traduções mais satisfatórias quanto a determinados termos de especialidade. Para Gile (2009), que descreve várias estratégias de como se pode melhor formar os tradutores, os recursos humanos são a forma mais poderosa de todas. 0 autor explica que um especialista pode fornecer informações confiáveis mais rapidamente do que qualquer livro ou banco de dados. Os falantes nativos da língua do texto-fonte podem fornecer detalhes deste, ao passo que os falantes nativos da língua do texto-alvo poderão melhor orientar os tradutores na produção final da tradução. Para Gile (2009: 142), quando o mesmo especialista é um falante nativo da língua do texto-alvo e compreende bem a língua do texto-fonte, a situação é, portanto, ideal. Assim, contar com a colaboração de um agente externo com conhecimentos linguísticos e que pertence ao mesmo ambiente acadêmico dos alunos, estando, portanto, acessível a eles, pode aumentar as chances de sucesso dessa abordagem.

$\mathrm{Na}$ sequência da atividade ora descrita, supõe-se que uma classe inteira esteja envolvida na realização do projeto de tradução. 0 professor de tradução, os alunos e o docente-cliente primeiramente negociam as condições sob as quais o projeto será realizado, e os alunos, com a assistência do professor, podem identificar e planejar os passos que seguirão para entregar ao docente-cliente uma tradução competente e passível de ser publicada.

A atividade pode percorrer cerca de cinco grandes etapas: na primeira etapa, devem ser definidos os papéis dos alunos. Sugere-se que os alunos trabalhem colaborativamente em pequenos grupos de aprendizado, compostos por três ou quatro alunos para cumprir as distintas fases do projeto. Com a orientação do professor, a classe nomeará dois gerentes de projetos que deverão organizar, moderar e agilizar os esforços dos alunos-terminólogos, alunos-tradutores e dos alunos-revisores. Assim, o projeto contará com os seguintes agentes: o docente-cliente (professor de uma determinada área do conhecimento do mesmo cenário acadêmico ao qual pertencem os alunos- 
tradutores), o gerente geral (o professor de tradução), os gerentes de projetos (um aluno responsável pelo gerenciamento geral do projeto e outro pelo manuseio e gerenciamento do sistema de memória de tradução que será utilizado como ferramenta tecnológica de apoio ao projeto), os tradutores (de quatro a cinco alunos, a depender do cenário de sala de aula), os terminológos (de três a cinco alunos responsáveis pelo levantamento terminológico do texto encomendado e dos textos de referência em língua materna, que poderão ser acoplados ao sistema de memória de tradução por meio das funcionalidades de acoplagem de corpus ou corpora eletrônicos), e os revisores (de três a cinco alunos que estarão responsáveis pela revisão geral e leitura minuciosa do texto traduzido). Os papéis exercidos pelos alunos podem se alternar em um projeto subsequente, para que todos experienciem as diversas etapas de elaboração de uma tradução.

Recomenda-se que um projeto colaborativo apenas seja implementado na sala de aula de ensino de tradução após os alunos já estarem familiarizados com as funcionalidades básicas de um sistema de memória de tradução e possuírem conhecimentos básicos sobre linguística de corpus e terminologia. Assim, um projeto autêntico e colaborativo de tradução, envolvendo quaisquer textos ou combinações linguísticas, poderia se constituir como um módulo posterior aos de iniciação às ferramentas de tradução, agregando conhecimento e manipulação de outras funcionalidades dos sistemas que visem a projetos colaborativos.

\section{Os sistemas de memória de tradução: funcionalidades que dão apoio à adoção de uma pedagogia colaborativa}

Os sistemas de memória de tradução são, basicamente, bancos de dados que armazenam pares de segmentos bilíngues, isto é, segmentos de um texto em língua $A$ e seu correspondente em língua $B$ em um único arquivo. Comumente denominados "memórias de tradução", esses sistemas se tornaram bastante populares a partir de 1990, principalmente por facilitar o 
trabalho do tradutor profissional, que passou a utilizar, em seus trabalhos, segmentos que já havia traduzido e armazenado no banco de dados dos sistemas durante trabalhos anteriores, podendo assim entregar com mais rapidez suas traduções a um mercado que corre contra o tempo (ESQUEDA; StUPIELLO 2016; EsQUeda et al. 2017).

Para além de simplesmente armazenar segmentos bilíngues em um banco de dados, tais sistemas, quando utilizados no ensino de tradução, podem servir à pedagogia colaborativa, através de algumas ferramentas e funcionalidades que lhe são características, como as demonstradas a seguir.

\subsection{0 gerenciamento de pacotes ${ }^{7}$}

Em um projeto colaborativo de tradução, os alunos, que irão atuar como gerentes de projetos, recebem o texto do docente-cliente, dividindo-o entre o grupo de alunos que irá traduzi-lo.

Como ainda não existe uma funcionalidade nos sistemas de memória de tradução que permita que um único documento seja dividido e distribuído em pacotes para os membros da equipe, uma solução possível é fragmentar o documento, neste caso um artigo científico de 30 páginas escrito em língua inglesa, por meio de ferramentas externas, agregar os documentos resultantes ao projeto e enviá-los em diferentes pacotes aos membros do grupo.

Depois de dividido o texto, através da funcionalidade de pacotes do sistema de memória de tradução, os gerentes realizarão a segunda etapa do projeto, qual seja de distribuição das tarefas e arquivos. Na atividade aqui descrita, o sistema de memória de tradução utilizado como exemplo é o SDL Trados Studio ${ }^{8}$.

\footnotetext{
70 presente trabalho é oriundo das atividades do projeto "Ferramentas tecnológicas para o ensino e a pesquisa na área de Tradução" (Edital $n^{\circ} 2 / 2017$; Projeto $n^{\circ} 495$ ), coordenado por mim, autora deste estudo, e financiado pelo Programa de Bolsas de Graduação da PróReitoria de Graduação e Divisão Discente da Universidade Federal de Uberlândia (UFU). Agradecimentos devem ser feitos à bolsista do projeto, Isabel Borges Ribeiro de Assunção Machado, aluna do Curso de Sistemas de Informação e do Curso de Bacharelado em Tradução da UFU, especialmente por seu auxílio na elaboração de tutoriais descritivos das funcionalidades do software SDL Trados Studio.

8 SDL Trados Studio para Windows. Versão 2017. Disponível em: <http://www.sdl.com>. Acesso em: 02 fev. 2019. Para a atividade aqui sugerida, utiliza-se a versão 2017 do sistema de memória de tradução SDL Trados Studio, em sua versão trial (versão teste gratuita
} 
Pacote, em referência a package, do inglês, é o nome dado a um conjunto de documentos produzido por sistemas de memória que reúne vários arquivos a serem traduzidos, materiais de referência, memórias de tradução, glossários, dicionários de autossugestão e demais dados de um determinado projeto.

Existem dois tipos de pacote no SDL Trados Studio: o de projeto e o de retorno. Os pacotes de projeto (project package) são criados pelos gerentes de projetos, que os enviam para tradução (ou revisão) aos vários tradutores, que os recebem e devolvem seus trabalhos em pacotes de retorno (return package). Cada um desses contém arquivos para os quais uma tarefa será realizada, como arquivos que foram traduzidos ou revisados, ou contendo uma tarefa que ainda precisa ser feita, como um arquivo enviado por um revisor a um tradutor, contendo uma determinada inconsistência a ser corrigida.

Os pacotes podem ser publicados em ambientes de transferência de arquivos, enviados por e-mail ou por qualquer outro método de preferência dos gerentes. Isso elimina a necessidade de enviar vários arquivos ou vários emails, e permite que todas as informações essenciais sejam enviadas com os arquivos do projeto numa estrutura integrada, propiciando a todos os alunos e o professor o acesso às partes e fases do projeto.

A criação de pacotes é realizada por meio de um assistente específico do SDL Trados Studio (Create Project Package Wizard). Todos os arquivos do projeto (ou alguns arquivos selecionados) podem ser agregados ao pacote, que ainda pode ser dividido e redistribuído conforme o tamanho ou pares linguísticos.

Os alunos designados para gerenciar o projeto de tradução, depois de dividirem o texto em seções, poderão, na tela inicial do SDL Trados Studio, na aba Projects, selecionar o projeto que desejam inserir no pacote e clicar na abaem Create Project Package, conforme mostra a Figura 1.

disponível durante 30 dias pela empresa SDL). Não foram testados outros sistemas de memória de tradução que possuem funcionalidades semelhantes, o que se constitui como uma frente futura de investigação. 
Figura 1: Criação do pacote no SDL Trados Studio.

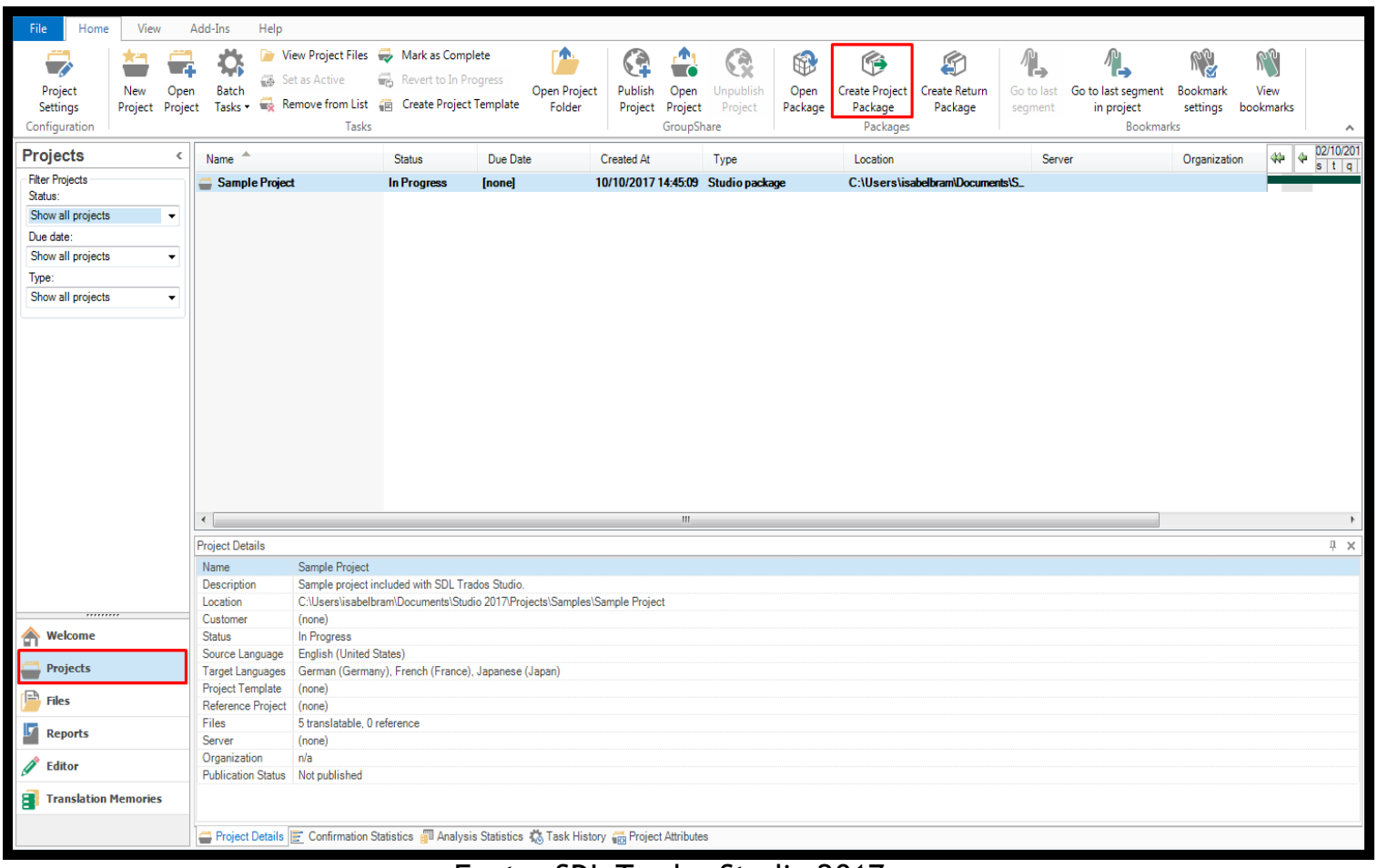

Fonte: SDL Trados Studio 2017.

Na sequência, os gerentes selecionarão os arquivos que irão compor o projeto. Para fins de ilustração, são exibidos, na Figura 2, vários arquivos de texto nomeados ficticiamente e que poderão fazer parte do pacote.

Figura 2: Tela de seleção de arquivos do assistente de criação de pacote do SDL Trados

Studio.

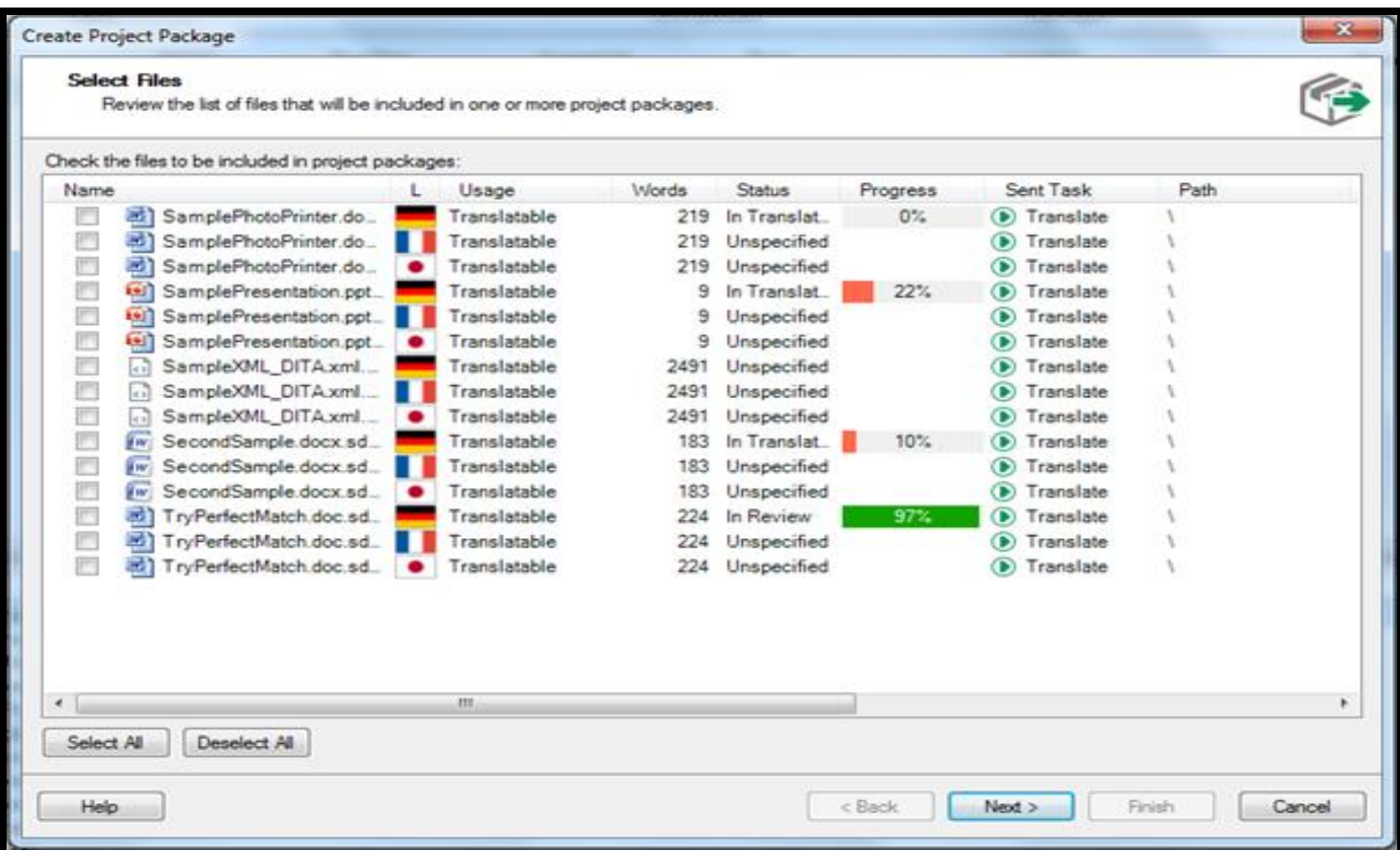

Fonte: Arquivos da autora.

TradTerm, São Paulo, v. 34, outubro/2019, p. 48-80 
É necessário escolher a pasta onde o pacote será armazenado. $\mathrm{Na}$ opção Create one package, é criado um único pacote para todos os arquivos do projeto. Em Create a package for every project language, podem ser criados múltiplos pacotes, sendo um para cada idioma, se este for o caso. Também é possível limitar o número de palavras designadas a cada pacote, conforme pode ser visto na figura a seguir, para que os alunos-tradutores traduzam de maneira equilibrada o mesmo, ou quase o mesmo, volume de texto.

Figura 3: Opções para a criação do pacote.

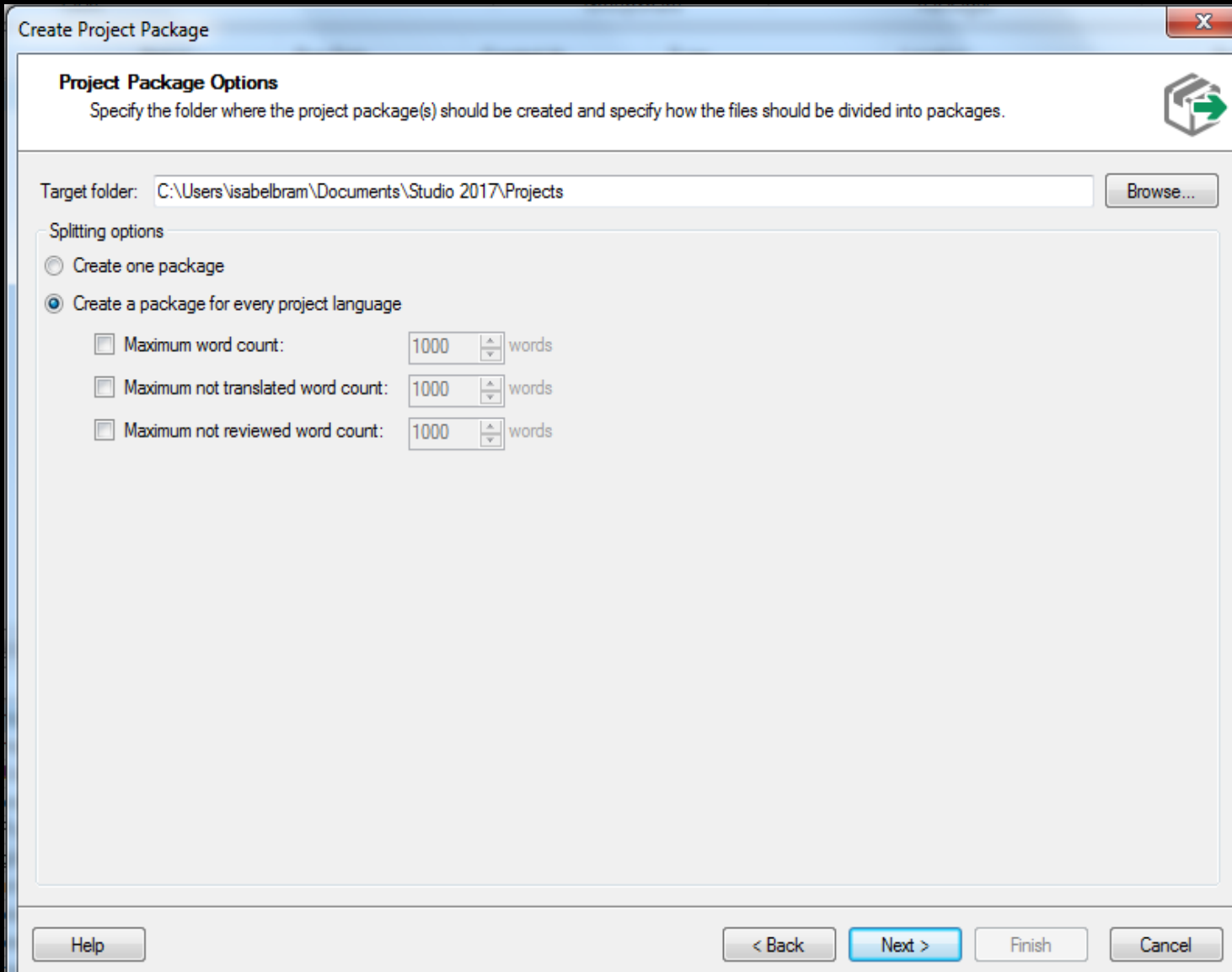

Fonte: SDL Trados Studio 2017.

Os gerentes também definirão alguns detalhes relacionados ao projeto, tais como: o nome do membro da equipe ao qual será designada a tradução de determinado arquivo do pacote, o prazo de entrega e quais arquivos serão enviados (Figura 4). 
Figura 4: Detalhes da configuração do pacote.

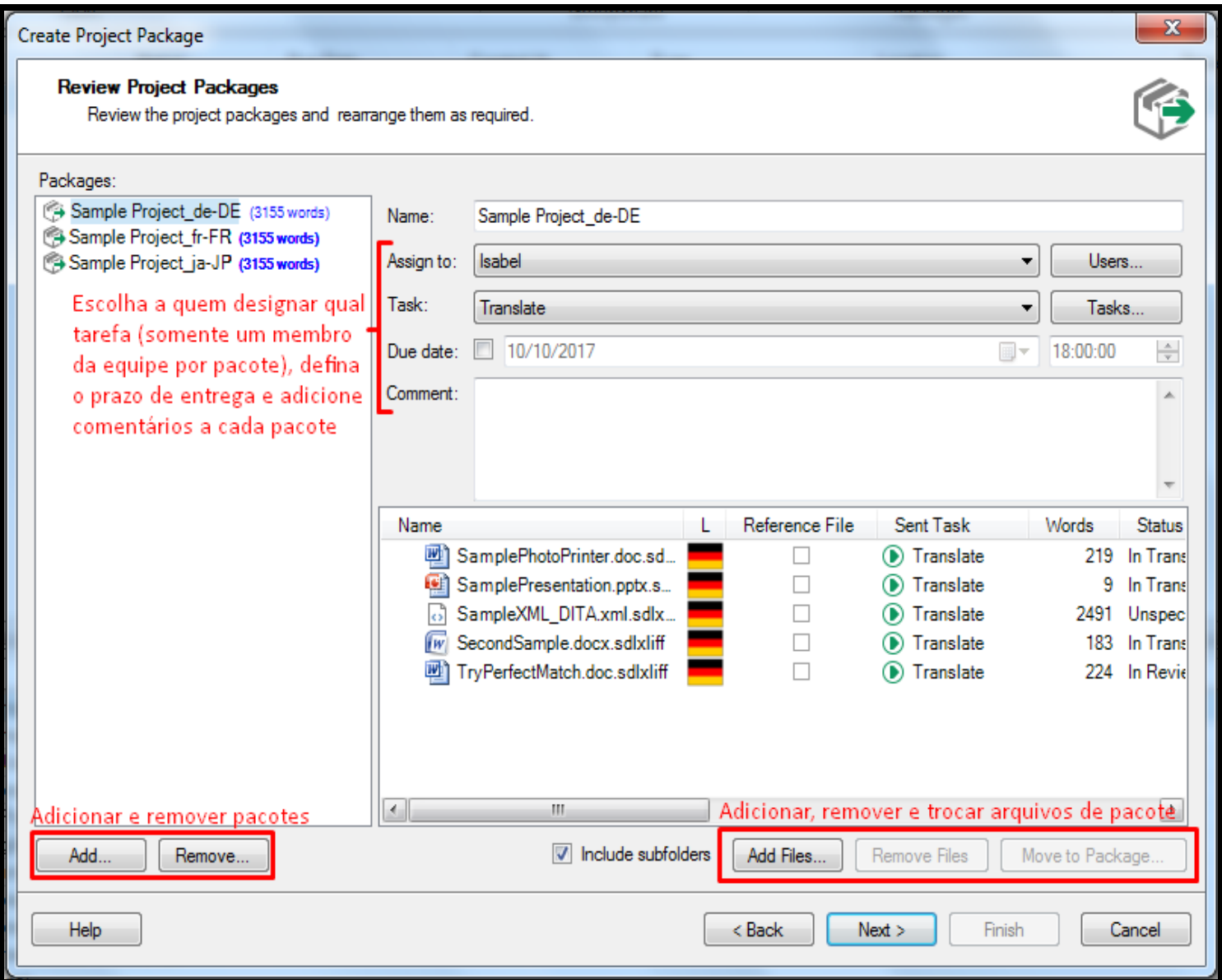

Fonte: Arquivos da autora.

A Figura 5 mostra quais recursos os gerentes poderão incluir no pacote, tais como: memórias de tradução, dicionários de autossugestão, glossários ou textos de referência. 
Figura 5: Possibilidades de inclusão de outros arquivos no pacote.

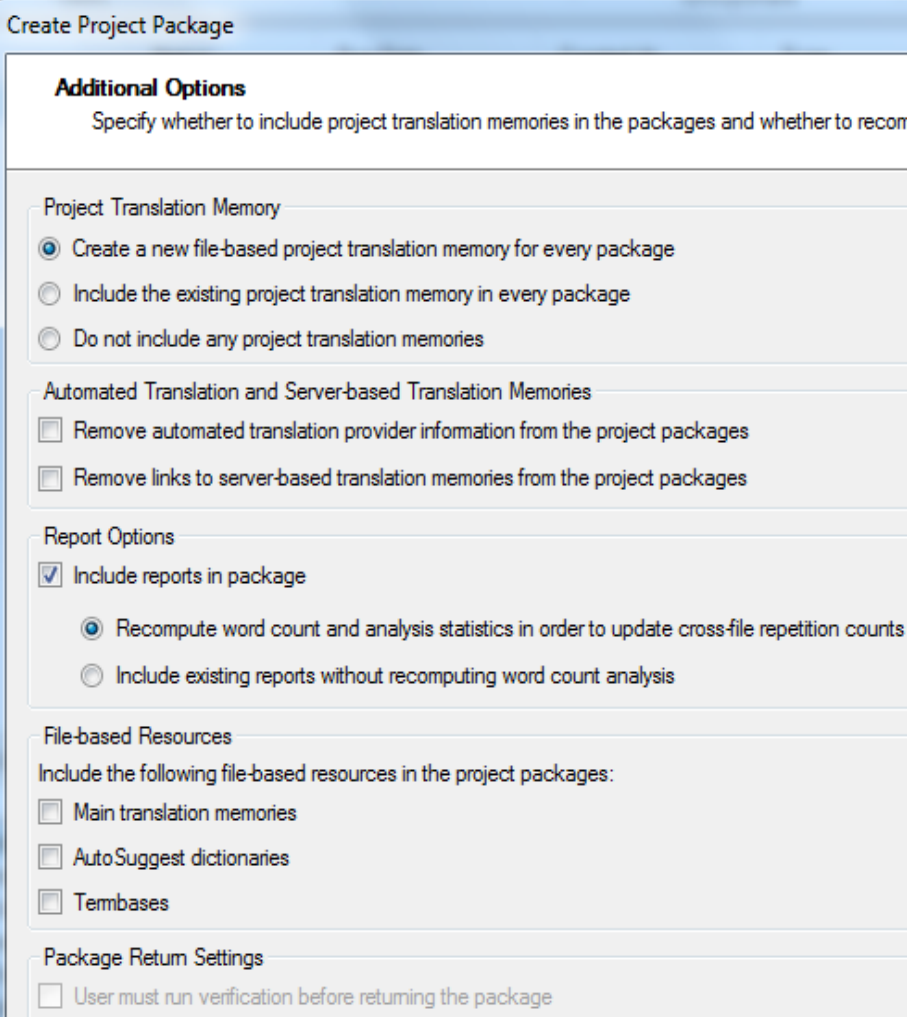

Fonte: SDL Trados Studio 2017.

Ao concluir o processo, os gerentes terão as seguintes opções: Send Package by Email, para enviar os pacotes aos alunos-tradutores via e-mail, ou Open Target Folder, para abrir a pasta de destino dos pacotes e salvá-los em pastas ou diretórios à escolha dos gerentes. Os pacotes são, portanto, arquivos comprimidos com extensão .sdlppx. 
Figura 6: Tela de finalização da criação do pacote e formas de envio aos tradutores.

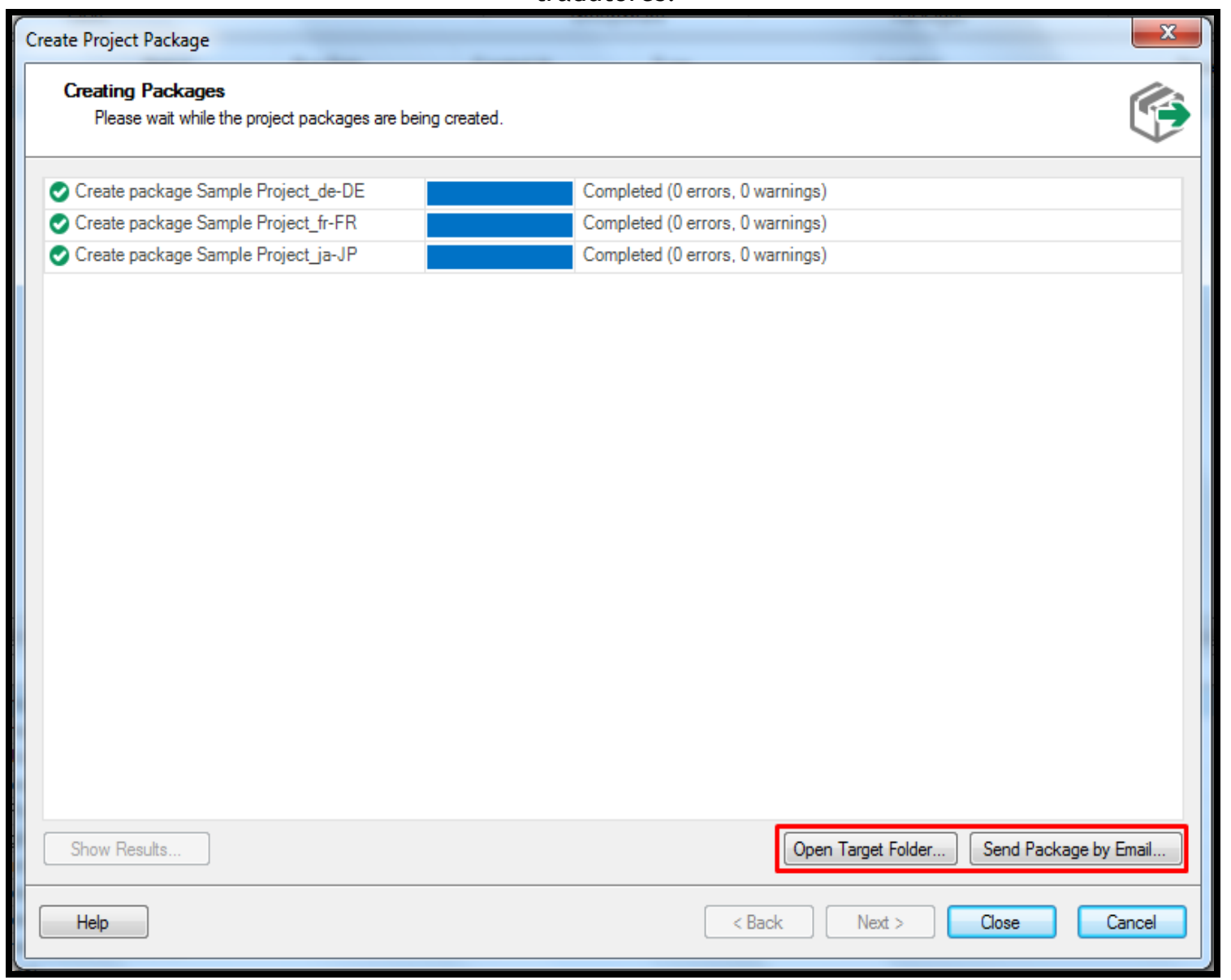

Fonte: SDL Trados Studio 2017; arquivos da autora.

Podemos afirmar, com base nessa e nas demais etapas da implementação do gerenciamento de pacotes para viabilização da pedagogia colaborativa que, cada vez mais, a tradução e seu ensino e aprendizagem vêm testemunhando a rápida expansão e proliferação da tecnologias que estão menos voltadas ao tradutor solitário, e mais focadas na criação de comunidades nas quais os aprendizes, ou profissionais, se veem trabalhando, aprendendo e traduzindo de forma colaborativa, como destacam Cordingley e Manning (2017), Cronin (2017) e Jiménez-Crespo (2017).

Além do assistente de criação de pacotes que pode ser utilizado nas versões gratuitas disponíveis por 30 dias do sistema SDL Trados Studio, o assistente SDL Group Share, também da mesma empresa SDL, atua sob o mesmo princípio, porém demandando, no caso dos contextos de ensino e aprendizagem, que as instituições disponibilizem versões pagas da ferramenta em seus laboratórios. No caso do SDL Group Share, não há a necessidade de se 
enviar os pacotes por e-mail ou salvá-los em diretórios, já que os usuários das versões pagas podem abri-los e editá-los no próprio ambiente de transferência de arquivos da ferramenta. Outros sistemas de memória de tradução disponíveis no mercado também reúnem essas mesmas funcionalidades, cabendo ao professor e às instituições de ensino a análise de qual poderá ser o melhor investimento a ser feito.

\subsection{Extração terminológica}

$\mathrm{Na}$ sequência das etapas, antes do início da tradução propriamente dita por parte dos alunos-tradutores, os alunos responsáveis pelo levantamento da terminologia e pelos textos de referência em língua materna na mesma temática do texto encomendado pelo docente-cliente, podem, como forma de pré-análise do texto original, averiguar os possíveis problemas ou desafios nele contidos, utilizando um plug-in gratuito que pode ser acoplado ao SDL Trados Studio, com o objetivo de dar apoio à tarefa de detecção de termos específicos.

Esse plug-in pode ser baixado gratuitamente do site da empresa SDL App Store e acoplado ao SDL Trados Studio. Trata-se de uma ferramenta que permite que os alunos responsáveis pelo levantamento terminológico do texto não apenas visualizem os termos mais recorrentes neste, como também extraiam um glossário monolíngue, ainda que preliminar, a partir da extração automática permitida pelo plug-in.

Após instalado o plug-in, na aba do projeto onde o texto original a ser traduzido está contido, ao selecioná-lo com o botão direito do mouse, os alunos-terminólogos irão acionar a última linha da janela que será aberta, intitulada Extract Project Terms, conforme mostra a Figura 7. 
Figura 7: Tela de seleção do texto original e abertura do plug-in Extract Project Terms.

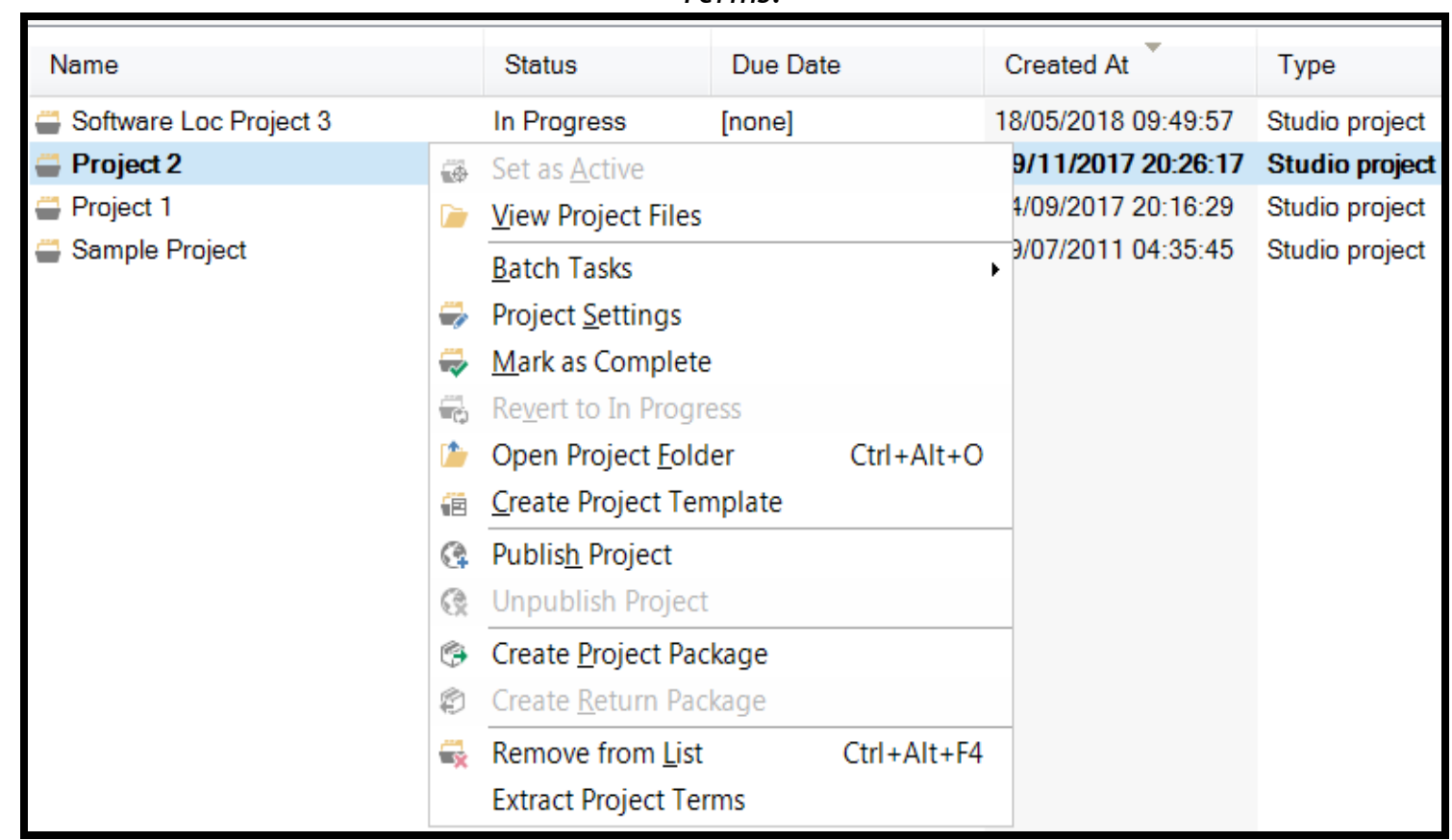

Fonte: SDL Trados Studio 2017.

Ao clicarem em Extract Project Terms, o sistema abrirá uma janela permitindo que os alunos-terminólogos extraiam os termos mais recorrentes do texto e, após discussão entre os membros desse grupo, os apresentem aos demais alunos da classe com suas possíveis sugestões de tradução. Essa etapa demandará que os alunos-terminólogos, também responsáveis pela busca de textos de referência, possam debater e confirmar as traduções mais satisfatórias para os termos possivelmente presentes em textos publicados na língua para a qual o texto será traduzido e que possuam a mesma temática de estudo. 
Figura 8: Tela inicial do plug-in Extract Project Terms.

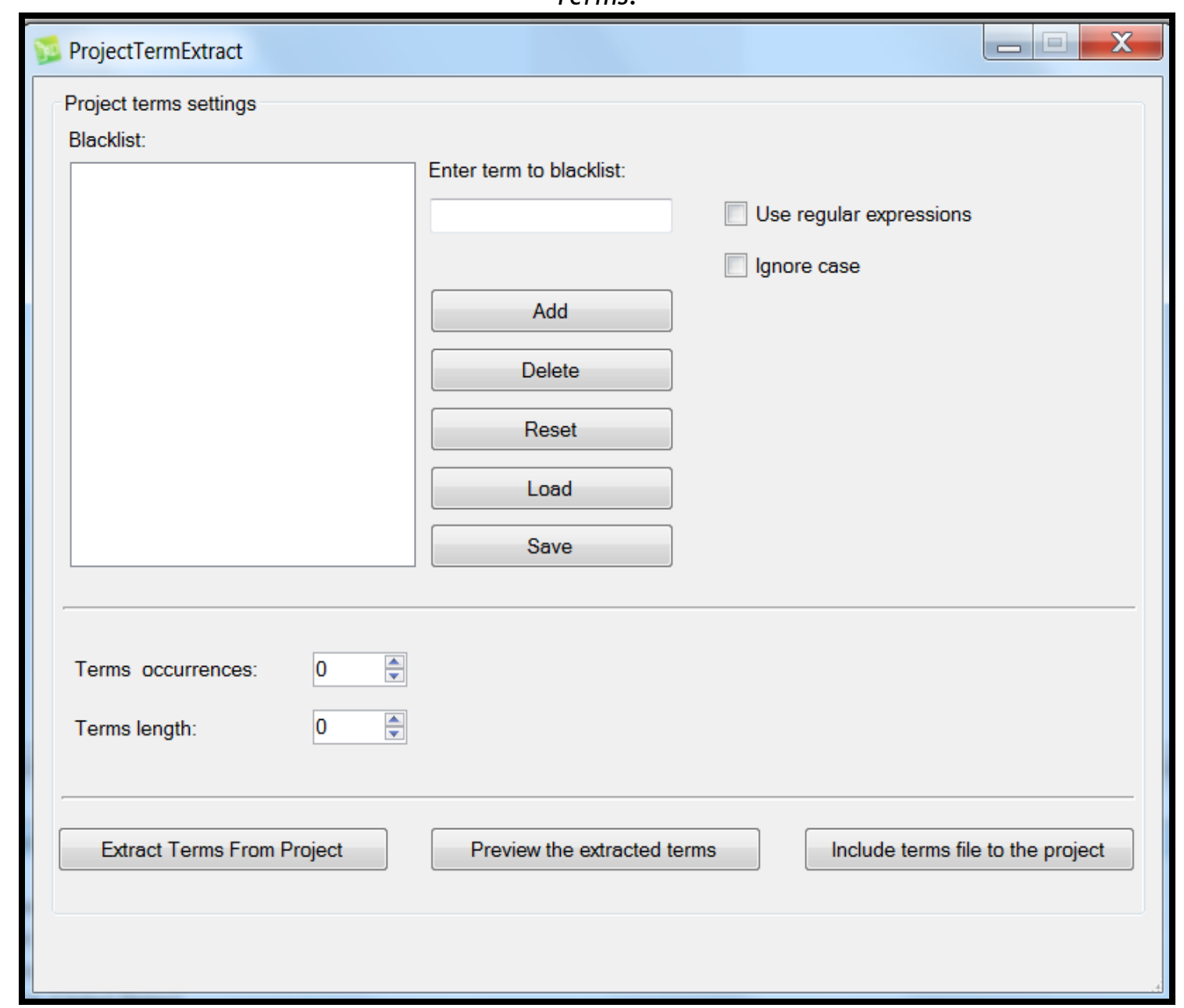

Fonte: SDL Trados Studio.

Nos campos Terms occurrences e Terms length (Figura 8), poderão ser definidos o número de ocorrências dos termos no texto e sua extensão, respectivamente, com o intuito de evitar que termos ou palavras formadas por poucas letras façam parte do glossário, o que busca excluir os artigos definidos, indefinidos, preposições, conjunções etc. Depois de demarcar, em tais campos, que se deseja verificar os termos que ocorrem dez ou mais vezes no texto, e que contenham o mínimo de dez letras, por exemplo, a funcionalidade Preview the extracted terms deverá ser acionada, para que os alunos-terminólogos tenham ideia de quais são os termos mais recorrentes no texto. O plug-in Extract Project Terms irá gerar uma word cloud (em português, “nuvem de palavras”), que será exibida na forma de um gráfico digital que mostra a frequência das palavras no texto (Figura 9). 
Figura 9: Nuvem de palavras exibida após a extração dos termos.

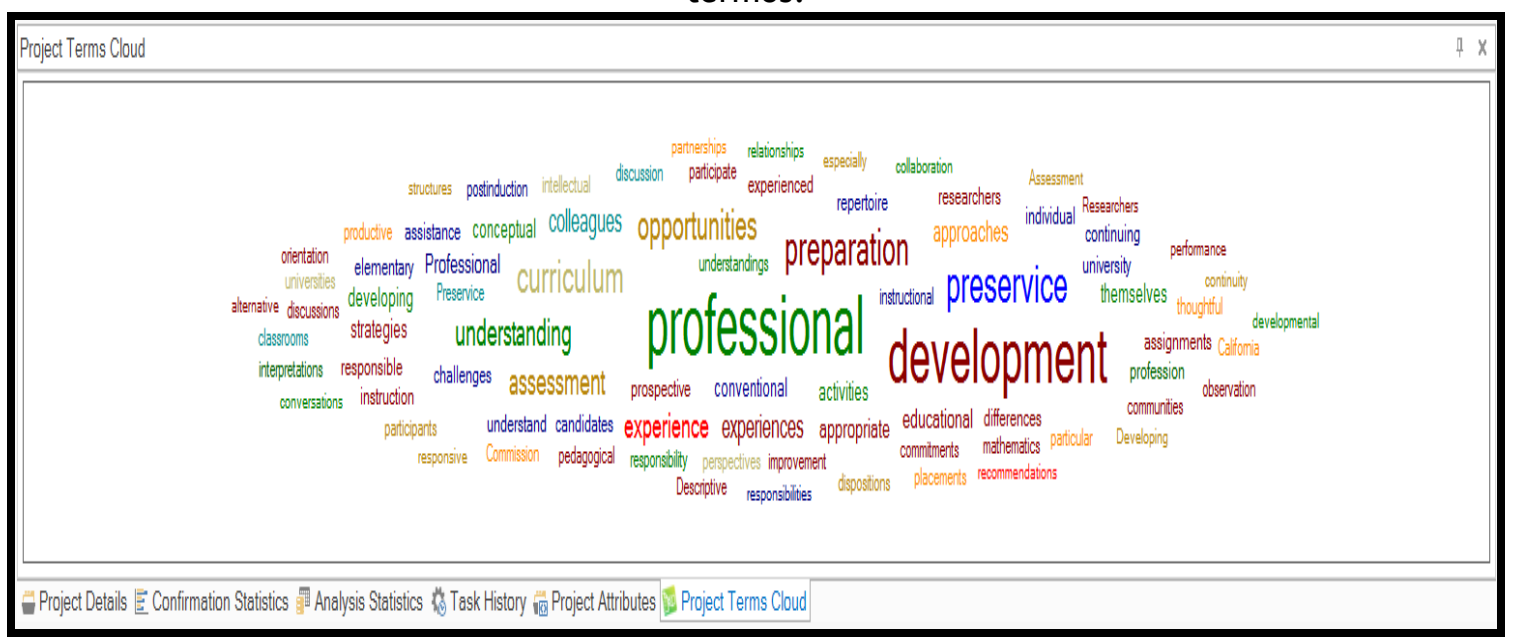

Fonte: Arquivo da autora.

Quanto mais a palavra é utilizada no texto, mais chamativa será sua representação no gráfico, isto é, maior a fonte em que é escrita e mais vibrantes serão suas cores. Assim, na Figura 9, podemos observar que as palavras professional, development, preservice, por exemplo, mostram-se relevantes em um texto da área de Educação, escolhido aleatoriamente para ilustrar essa etapa do projeto colaborativo.

Depois de gerar a nuvem de palavras, os alunos-terminólogos podem decidir quais delas farão parte de um glossário ou banco de dados terminológico, que poderá ser acoplado ao projeto, e consultado pelos alunos que irão traduzir o texto e aqueles que, posteriormente, irão revisá-lo. Clicando no botão Include terms file to the Project (Figura 8), a nuvem de palavras será transformada em um glossário (Figura 10). 
Figura 10: Glossário gerado a partir da nuvem de palavras extraída pelo plug-in Extract Project Terms.

\begin{tabular}{|c|c|c|}
\hline \multicolumn{3}{|c|}{ Artigo Feiman-Nemser - Demarcado por aluno v2.docx sdlxliff [Translation] } \\
\hline & [Project 2_2017_11_09_20_27.xml & \\
\hline 1 & professional & $\square$ \\
\hline 2 & development & $\square$ \\
\hline 3 & preservice & $\square$ \\
\hline 4 & preparation & $\square$ \\
\hline 5 & curriculum & $\square$ \\
\hline 6 & opportunities & $\square$ \\
\hline 7 & understanding & $\square$ \\
\hline 8 & assessment & $\square$ \\
\hline 9 & experience & $\square$ \\
\hline 10 & experiences & $\square$ \\
\hline 11 & colleagues & $\square$ \\
\hline 12 & approaches & $\square$ \\
\hline 13 & appropriate & $\square$ \\
\hline 14 & Professional & $\square$ \\
\hline 15 & educational & $\square$ \\
\hline 16 & conventional & $\square$ \\
\hline 17 & conceptual & $\square$ \\
\hline 18 & themselves & $\square$ \\
\hline 19 & developing & $\square$ \\
\hline 20 & activities & $\square$ \\
\hline 21 & strategies & $\square$ \\
\hline 22 & challenges & $\square$ \\
\hline 23 & candidates & $\square$ \\
\hline 24 & university & $\square$ \\
\hline 25 & prospective & $\square$ \\
\hline 26 & repertoire & $\square$ \\
\hline
\end{tabular}

Fonte: Arquivo da autora.

\subsection{A acoplagem dos textos de referência}

Para a acoplagem de textos de referência que tratem da mesma temática do texto-fonte publicados na língua para a qual o texto será traduzido, neste caso a língua portuguesa, podem ser utilizados os mesmos passos de acoplagem de textos a serem traduzidos em sistemas de memória de tradução. A diferença está na opção que pode ser selecionada após o carregamento dos textos. Em vez de ser selecionado para tradução, ao se clicar com o botão direito do mouse sobre o texto carregado, pode-se selecionar se se trata de um texto traduzível (que será convertido em 
SDLXLIFF9), localizável (que carrega gráfico e não será convertido em SDLXLIFF) ou de referência (destinado apenas a consultas), sendo este o caso.

Figura 11: Tela de escolha do status de um texto no projeto.

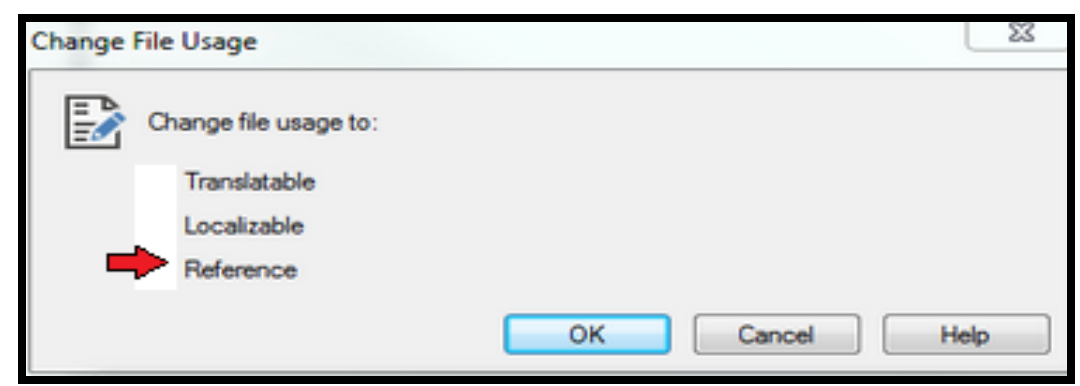

Fonte: SDL Trados Studio 2017.

Ao configurar determinados textos como textos de referência, eles constarão no projeto e poderão ser consultados no ambiente da ferramenta, porém não servem a buscas com os concordanciadores, como no caso de consultas utilizando a funcionalidade Concordance Search presente nos sistemas. Tal acoplagem apenas agiliza o trabalho dos tradutores e revisores, que não necessitarão sair do ambiente da ferramenta para acessar quaisquer informações sobre esses textos em outras pastas, diretórios ou na internet.

Finda essa etapa, após receberem "via pacote" o texto-fonte, o glossário, os textos de referência ou outras orientações dos gerentes de projetos, os alunos que irão traduzir o texto deverão clicar em Open Package e procurar o arquivo com extensão .sdlppx enviado pelo gerente de projetos (Figura 12).

\footnotetext{
9 XLIFF é um formato baseado em XML criado para padronizar a maneira como os dados traduzíveis e localizáveis são visualizados nos sistemas de memória de tradução durante um processo de tradução. Trata-se também de um formato comum para troca de dados entre ferramentas de apoio à tradução ou CAT tools (Computer Assisted Translation tools). No caso, os arquivos .sdlxliff levam a designação inicial de que foram criados na ferramenta da empresa SDL.
} 
Figura 12: Tela de acesso à abertura do pacote pelos alunostradutores.

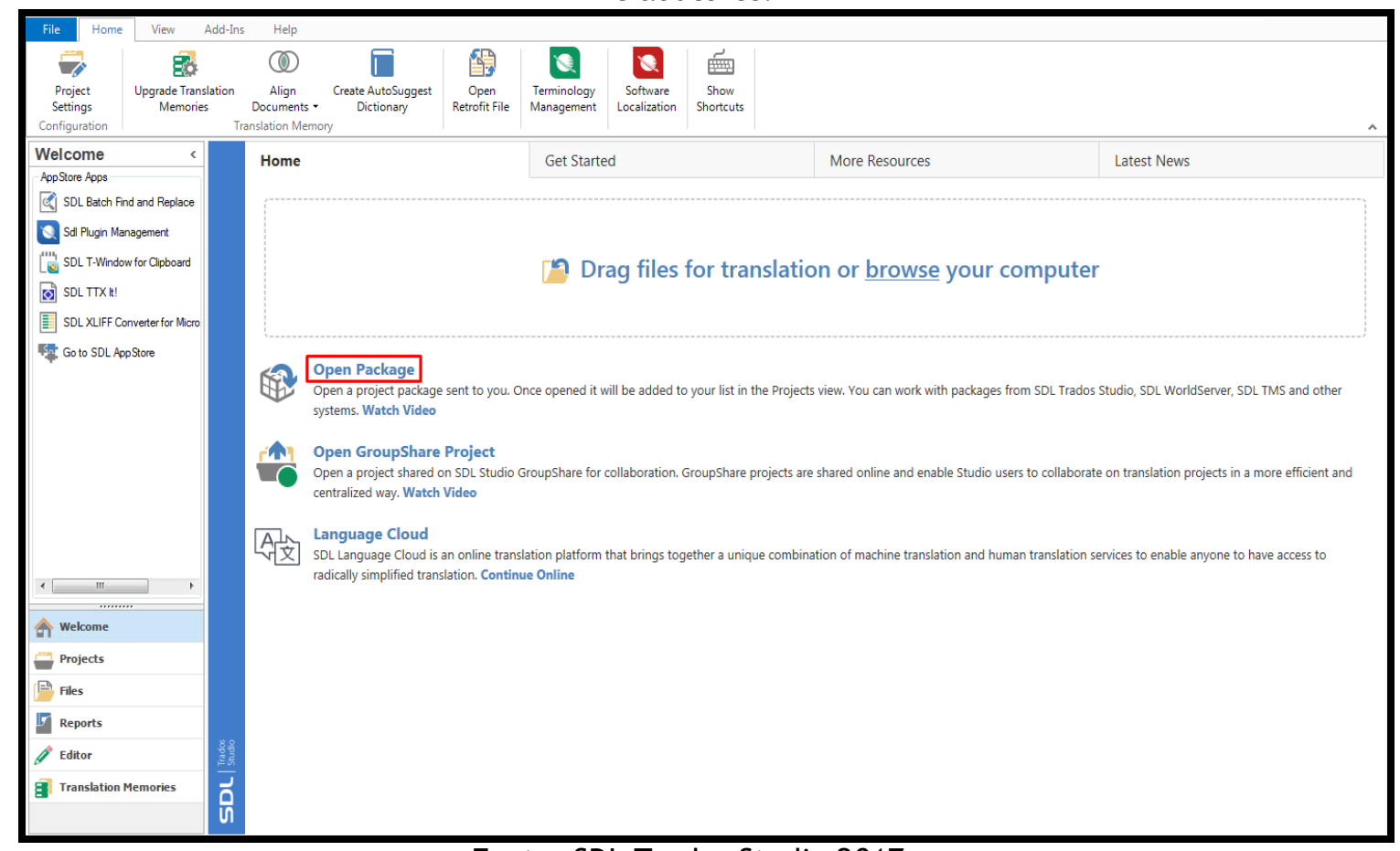

Fonte: SDL Trados Studio 2017.

Na sequência, será necessário confirmar os dados do projeto e abri-lo para o início da tradução. 
Figura 13: Tela de abertura do pacote.

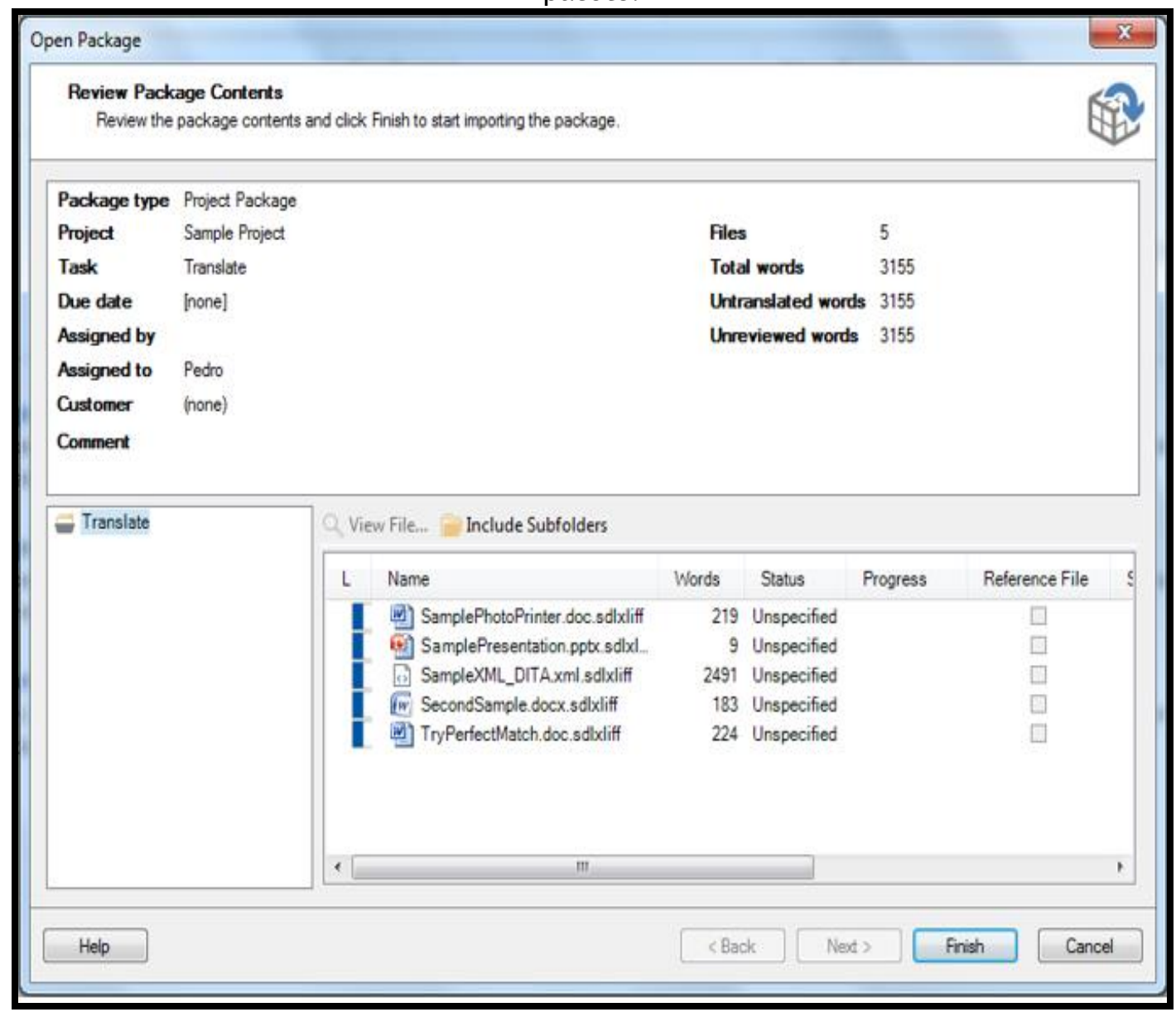

Fonte: Arquivos da autora.

\subsection{Os pacotes de retorno e a união das memórias de tradução}

A partir das contribuições dos colegas das etapas anteriores, os alunos-tradutores deverão realizar a tradução e, após concluí-la, clicar em File para salvar os arquivos traduzidos. Na tela Projects, os alunos-tradutores selecionam o projeto e clicam em Create Return Package, em português “Criar Pacote de Retorno”. Ao confirmar os documentos que serão enviados ao gerente e a pasta onde será armazenado, o pacote de retorno pode ser finalizado. O pacote de retorno possui extensão .sdlrpx e deverá conter a memória de tradução produzida pelos alunos-tradutores. 
Figura 14: Tela de criação do pacote de retorno.

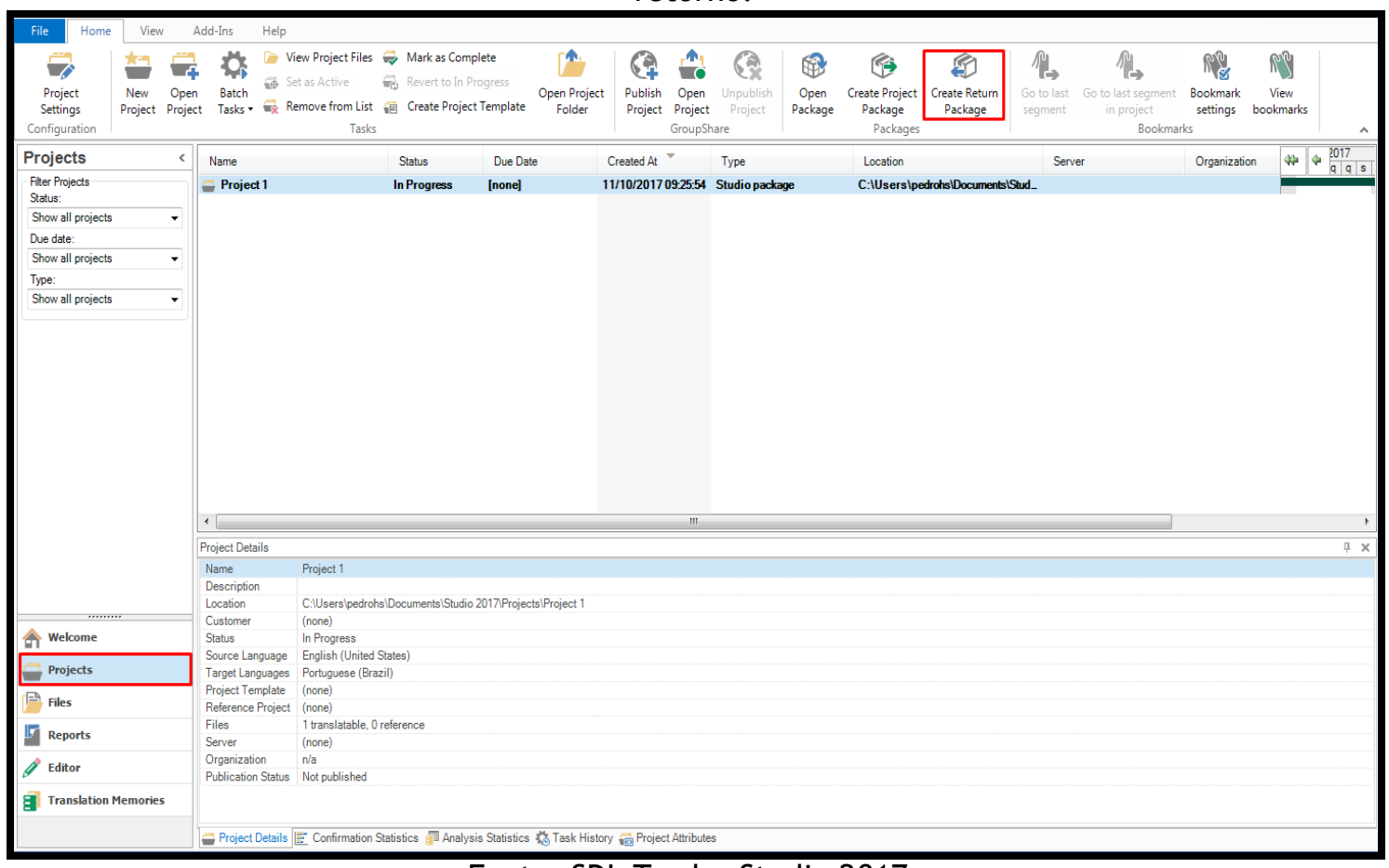

Fonte: SDL Trados Studio 2017.

Em Open Package, os gerentes de projetos selecionam o pacote de retorno, que possui extensão .sdlrpx.

Figura 15: Tela de acesso ao pacote de retorno.

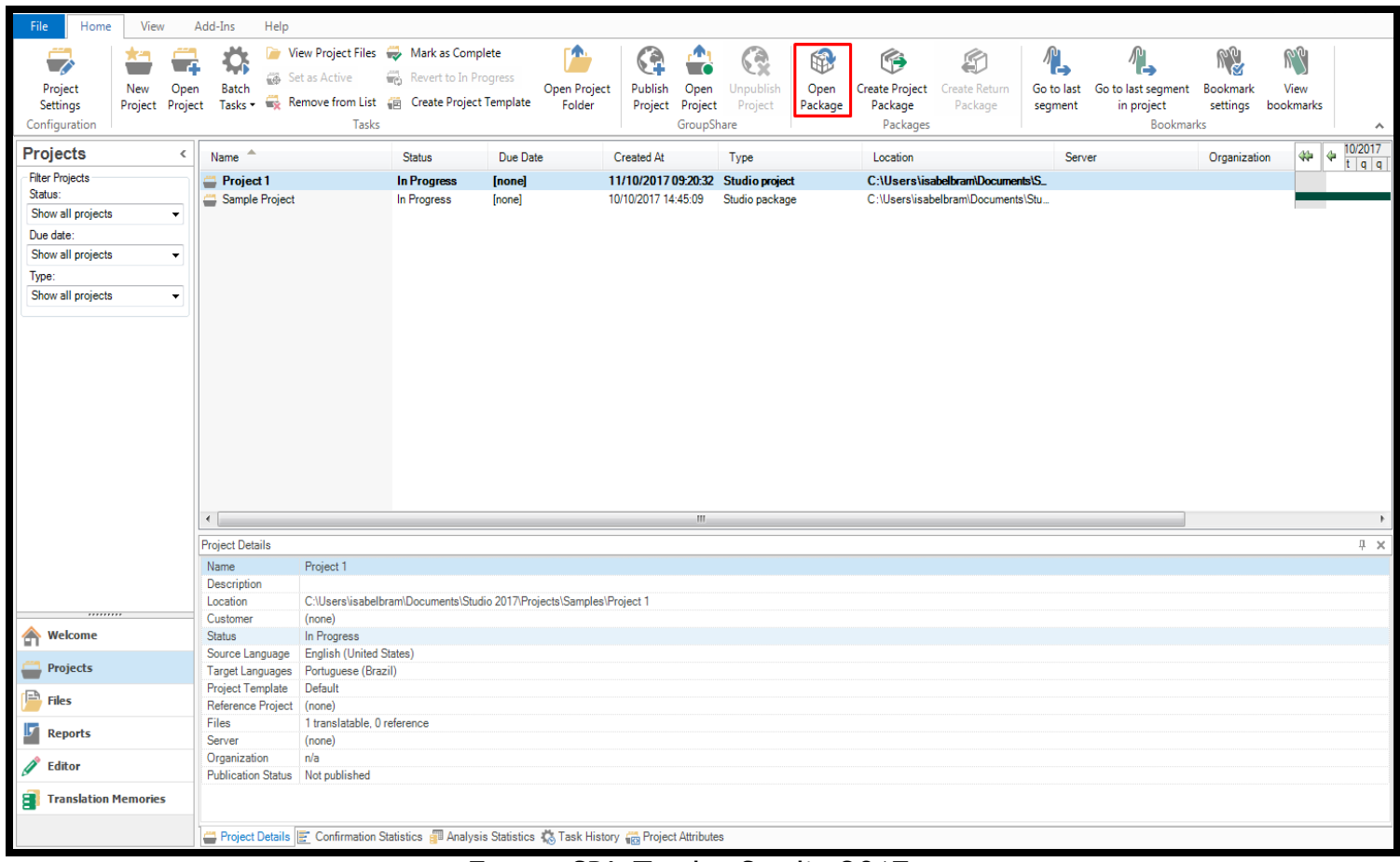

Fonte: SDL Trados Studio 2017.

TradTerm, São Paulo, v. 34, outubro/2019, p. 48-80 www.revistas.usp.br/tradterm 
Os gerentes conferem os dados do projeto e unem as memórias de tradução de todos os alunos, podendo transformá-las em uma única memória, clicando em Batch Tasks e, na sequência, em Update Main Translation Memories.

Figura 16: Tela de atualização da memória de tradução do pacote.

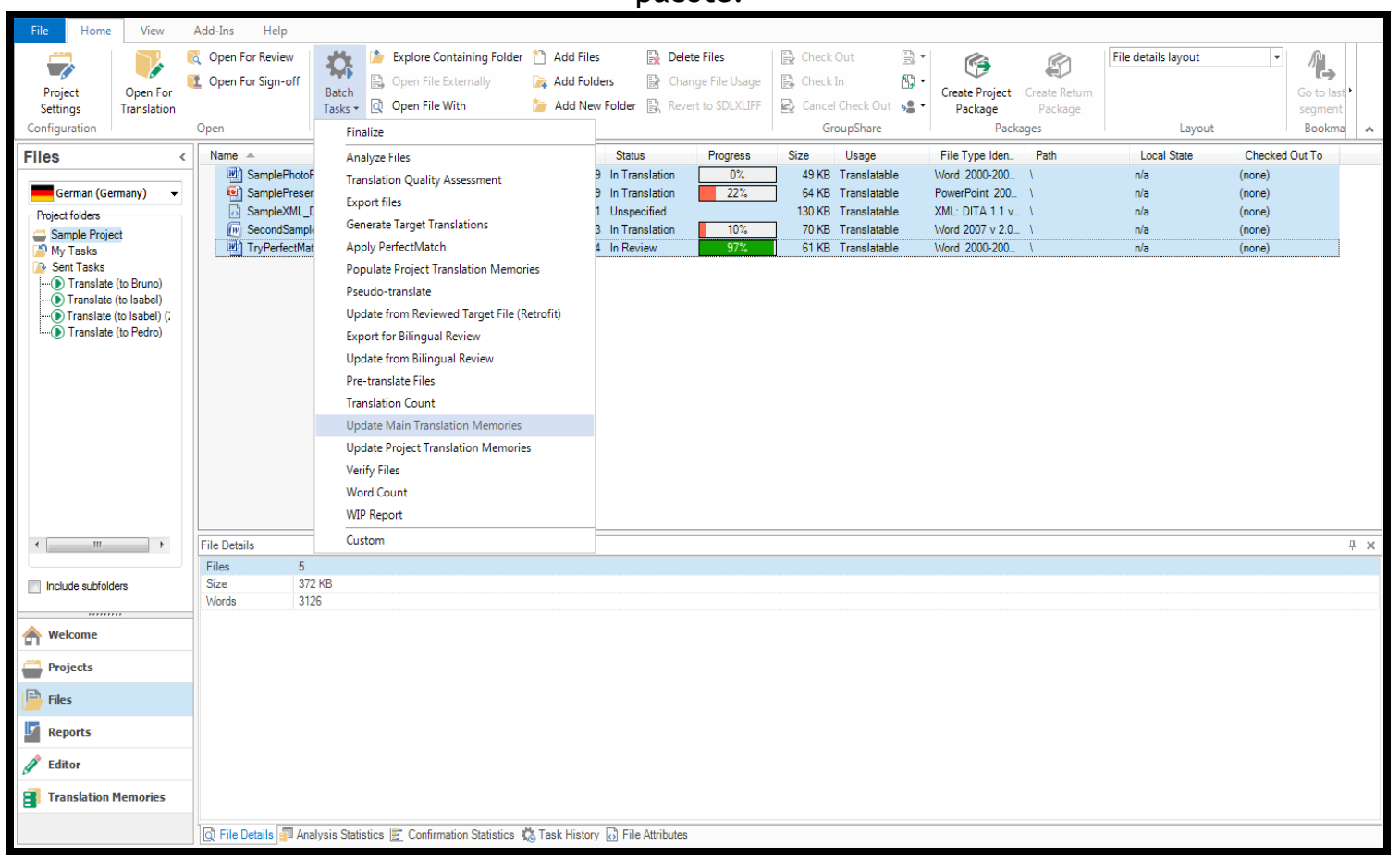

Fonte: Arquivos da autora.

Vale ressaltar que as memórias de tradução são designadas aos pacotes de acordo com a natureza de cada um deles. Se forem atribuídos todos os arquivos do projeto ao pacote, todas as respectivas memórias de tradução estarão a ele associadas. Caso o pacote contenha uma parte dos arquivos, somente a parcela relevante da memória pode ser utilizada. 
Figura 17: Função de união de memórias de tradução.

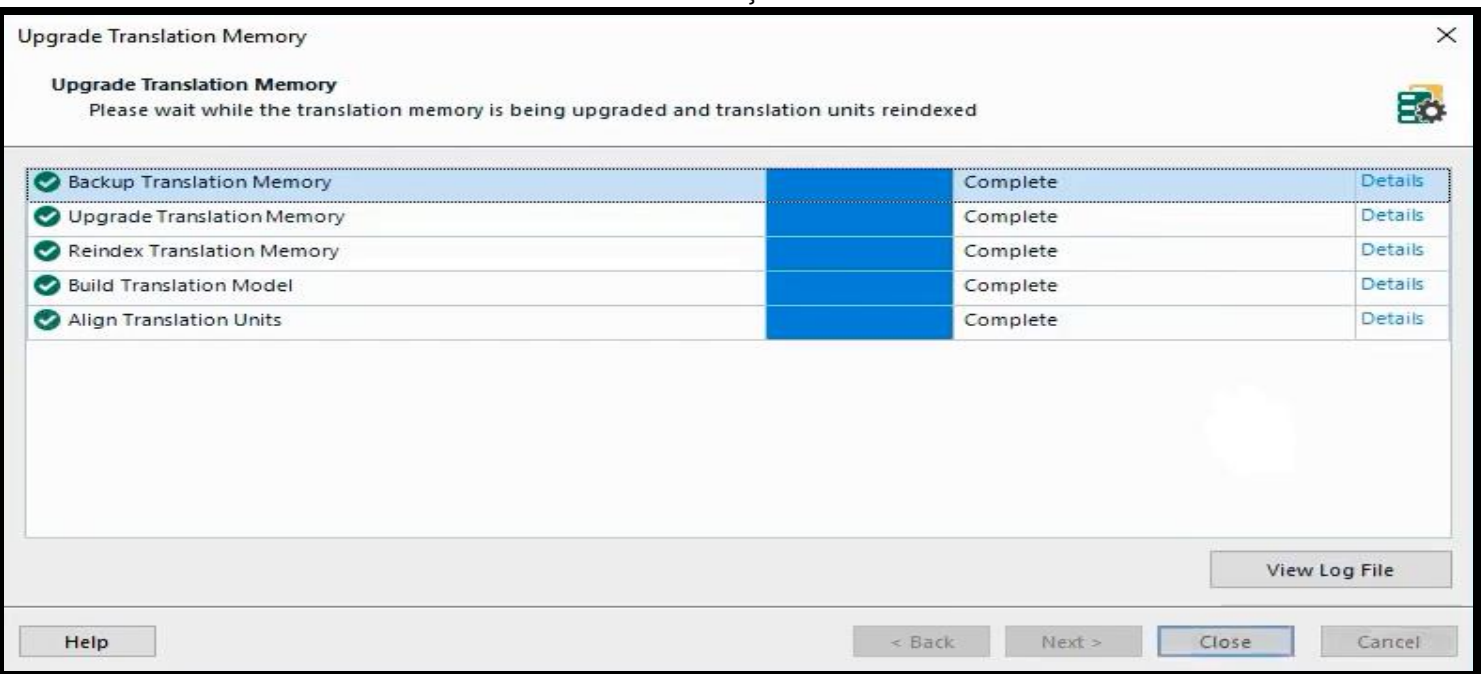

Fonte: SDL Trados Studio 2017.

Após tal etapa, os gerentes de projeto enviarão o pacote, com a memória de tradução, os glossários e os textos de referência atualizados aos alunos-revisores, que deverão realizar o mesmo procedimento de abertura, edição e retorno do pacote. Ao consultarem o glossário elaborado pelo alunosterminólogos, os textos de referência por eles agrupados e a tradução, os alunos-revisores poderão dar consistência à tradução antes de retorná-la aos gerentes de projeto e ao gerente geral (o professor de tradução), que também deverão ler a tradução na íntegra e, se necessário, compará-la com o original, consultar os glossários ou os textos de referência, a fim de realizar os últimos ajustes.

Na perspectiva de Kiraly (1995, 2000, 2014), González-Davies (2017) e Pitkäsalo e Ketola (2018), a interdependência, na pedagogia colaborativa, entre os trabalhos executados pelos alunos revela a importância da interação social, das discussões com relação à diversidade de opções tradutórias adotadas pelos alunos-tradutores, do cumprimento de prazos e do desempenho responsável por todos os envolvidos no projeto. Para esses autores, nos métodos transmissionistas de ensino, em que o professor é o único responsável por transmitir o conhecimento no formato da conferência magistral (ESQUEDA 2018) e os alunos devem memorizá-lo para em seguida preencher as questões de um exercício de tradução ou de uma prova, não há lugar para a interdependência, para os agentes, os prazos ou para a 
aprendizagem conjunta acerca dos processos de elaboração de uma tradução. A diferença entre uma abordagem e outra pode residir no fato de que a pedagogia colaborativa constrói a memória de longo prazo dos alunos, protegendo-os do rápido esquecimento dos conceitos, definições, processos e etapas de elaboração de uma tradução, possibilitando que ativamente vivenciem os desafios de um projeto similar ao que encontrarão na vida profissional. Para Cormier (1998), a abordagem transmissionista outorga grande importância à memorização da quantidade de conhecimentos transmitidos pelo professor, porém os alunos rapidamente se esquecem do que estudaram após realizarem as provas ou entregarem suas traduções.

Para concluir, após terminado o processo geral de revisão, pode-se submeter a tradução do texto traduzido pelos alunos à leitura do docentecliente que encomendou a tradução, buscando fazer uso da função contributiva dos agentes externos, que, na perspectiva de Gile (2009), como já apontado, exerce papel crucial na formação de tradutores.

Embora esta proposição didática tenha particularizado algumas das principais ferramentas e funcionalidades contidas e a serem acopladas a um sistema de memória de tradução que visa projetos colaborativos, a intenção é a de que, na pedagogia colaborativa, o alunos exercitem, de forma ativa, a complexidade de quaisquer projetos tradutórios desde o seu início, fazendo com que tomem ciência de que todos elementos situacionais do projeto podem servir como pontos de referência rumo à tradução satisfatória. Isso implica uma mudança obrigatória nos papéis desempenhados por professores e alunos em sala de aula. O desenho da atividade de tradução não é tarefa única e exclusiva do professor, mas de todos os envolvidos na comunidade de prática.

\section{Alguns encaminhamentos}

A presente proposição didática teve como foco principal a descrição de atividades que buscam envolver os alunos em projetos autênticos e colaborativos de tradução, cerceados pelas tecnologias disponíveis a tal fim. 
As possibilidades de atividades aqui descritas se iniciam com o recebimento do texto encomendado pelo docente-cliente, na divisão das tarefas, na tomada de consciência dos alunos acerca das demandas requeridas dos vários agentes envolvidos e na manipulação de funcionalidades específicas de um sistema de memória de tradução propícias à pedagogia colaborativa.

Respeitando uma sequência de atividades, a pedagogia colaborativa assistida por um sistema de memória de tradução pode tornar a aprendizagem contextualizada, isto é, situada em relação ao conhecimento adquirido gradualmente pelos alunos durante o processo de elaboração de uma tradução, que passam a lidar com as dificuldades inerentes ao texto-fonte, o manejo das ferramentas tecnológicas, as necessidades de seu grupo, os prazos estipulados junto ao docente-cliente e aos gerentes de projeto, dentre outros.

Em vez de buscar desenvolver as habilidades e os conhecimentos sobre tradução por meio de exercícios simulados, pedagogia essa que normalmente ocorre nas fases iniciais da formação de tradutores (GILE 2009), a descrição dessa atividade visa tornar a cena pedagógica altamente realista e colaborativa, conforme explica Kiraly (2000).

O processo completo de elaboração da tradução, embora planejado, poderá ainda conter outras etapas e fases que surgirão espontaneamente a partir do trabalho conjunto dos alunos. Em vez de caber ao professor elaborar atividades que simulem sub-tarefas de tradução, seu papel poderá ser o de auxiliar os alunos na identificação dos aspectos de suas competências atitudinais e instrumentais que não estão desenvolvidas o suficiente para completar o trabalho de tradução em questão, e prover suporte para a aquisição das habilidades e dos conhecimentos necessários.

Nesse prisma, o objetivo da inserção da pedagogia colaborativa passa a ser o de aprender a compartilhar o conhecimento, a agir, refletir e solucionar conflitos de forma conjunta. Nas palavras de Kiraly (2014) e Echeverri (2008), uma vez que as experiências de aprendizagem mais valiosas são as experiências autênticas, é essencial contextualizar a aprendizagem. Fornecer uma tarefa imaginária de tradução certamente terá algum impacto, embora muito limitado, na autenticidade da situação. Se usada numa aula 
convencional, as tarefas didáticas inventadas pelo professor serão julgadas, muitas vezes, pela precisão e aceitação dos parâmetros arbitrários ou de critérios idiossincráticos do professor. Mesmo no melhor dos casos, ainda não haverá uma situação de tradução autêntica e tampouco uma avaliação do mundo real fora da sala de aula. E é precisamente essa ligação com o mundo exterior ao da sala de aula que parece ser a chave para se abordar uma situação de tradução realista (KIRALY 2014).

Por meio da pedagogia colaborativa, concebe-se o ambiente escolar como um contexto social, humano e dialógico como outro qualquer (GonzálezDAVIES 2017), possibilitando que os alunos atuem como profissionais que efetivamente interagem com outros agentes envolvidos no processo de tradução.

Em se tratando dos sistemas de memória de tradução, pode-se dizer que o ensino de suas funcionalidades, vantagens e desvantagens, por si só, não garante a qualidade das traduções produzidas (EsQUedA; STUPIELLO 2016; EsqueDA et al. 2017), principalmente quando o foco da atividade didática é o produto final. No entanto, com base na sequência das atividades ora descritas, tais sistemas, ao serem utilizados a partir de uma abordagem colaborativa de ensino, podem se tornar um recurso valioso que leva a cabo o trabalho conjunto realizado pelos alunos, e que não descarta ou desvaloriza o longo processo que toda tradução percorre para se concretizar. Tudo depende da abordagem de ensino escolhida para fazer uso dos sistemas.

Para finalizar, vale ressaltar que esta proposição didática, de cunho teórico, carece de aplicação em ambiente real de ensino e aprendizagem, prospectando a implementação de uma pesquisa de viés naturalista e de testagem qualitativo-experimental (GILE 2009), principalmente com o propósito de examinar, a partir de relatos de alunos (em grupos ou individuais), se eles compreendem que uma comunidade de prática (WENGER 1998; KIRALY 2000; GONZÁLEZ-DAVIES 2017) é diferente de uma equipe que tem interesses em comum, mas, em vez disso, é definida como produção compartilhada do conhecimento, e não da tarefa. Na perspectiva de uma pesquisa naturalista, será necessário avaliar se as crenças e concepções que os alunos trazem consigo à sala de aula sobre o que é aprender a traduzir 
(Esqueda; OliveIRA 2013) e sobre quais os papéis que professores e alunos podem desempenhar não entram desfavoravelmente em conflito com uma abordagem mais flexível, plástica e imprevisível, como é o caso da pedagogia colaborativa.

A pedagogia colaborativa que forma uma comunidade de prática é determinada pelo valor que o conhecimento produzido tem para seus membros e não para a instituição ou para o currículo de um curso (KIRALY 2000). Nessa pedagogia, as dificuldades com os textos a serem traduzidos e com as ferramentas tecnológicas a serem manipuladas não surgem quando o projeto é iniciado e não terminam com ele, mas mantém a comunidade de prática ativa.

\section{Referências bibliográficas}

Chesterman, A. Bridge Concepts in Translation Sociology. In: Wolf, M.; FuKarI, A. Constructing a Sociology of Translation. Amsterdam / Philadelphia: John Benjamins, 2007: 171-183.

CoRdingley, A.; MANNING, C. F. (org.) Collaborative Translation: From the Renaissance to the Digital Age. London/New York: Bloomsbury Publishing, 2017.

CORMIER, M. En torno a una pedagogía centrada en el estudiante: el método "Aprendizaje a través de problemas" aplicado a la terminología. Onomazein, $\mathrm{n}^{\circ}$ 3, 1998, pp. 177-193. Disponível em: <http://onomazein.letras.uc.cl/03_Numeros/N3/N3.html>. Acesso em: 22 maio 2019).

CRONIN, M. A New Ecology for Translation: Collaboration and Resilience. In: CoRdINGLEY, A.; MANNING, C. F. (org.) Collaborative Translation: From the Renaissance to the Digital Age. London/New York: Bloomsbury Publishing, 2017: 233-246.

ECHEVERRI, Á. Énième plaidoyer pour l'innovation dans les cours pratiques de Traduction. Préalables à L'innovation? Montréal: TTR: Traduction, Terminologie, Rédaction, vol. $21, \mathrm{n}^{\circ} 1$, 2008, pp. 65-98. Disponível em: <http://id.erudit.org/iderudit/029687ar>. Acesso em: 02 out. 2018.

EsquedA, M. D. Ensino de Tradução: Culturas Pedagógicas. Trabalhos em Linguística Aplicada, Campinas, vol. 57, $\mathrm{n}^{\circ}$ 2, 2018, pp. 1244-1273. 
Disponível

em:

<https://periodicos.sbu.unicamp.br/ojs/index.php/tla/article/view /8651880/18340>. Acesso em: 03 jan. 2019.

EsquedA, M. D. et al. Examinando o uso dos sistemas de memória de tradução na sala de aula de tradução. Cadernos de Tradução, vol. 37, no 3 , 2017, pp. 160-184. Disponível em: <https://periodicos.ufsc.br/index.php/traducao/article/view/21757968.2017v37n3p160/34849>. Acesso em: 03 jan. 2019.

Esqueda, M. D.; Stupiello, E. N. A. A critical approach proposal for training translation memory systems in translator education programs. FORUM. Revue internationale d'interprétation et de traduction/International Journal of Interpretation and Translation John Benjamins, vol. 14, nº 1, 2016, pp. 79-99.

Esqueda, M. D.; Oliveira, K. I. Crenças e concepções do tradutor em formação. Tradução em Revista, vol. 14, n 1, 2013, pp. 138-166. Disponível em: <https://www.maxwell.vrac.puc-rio.br/22051/22051.PDFXXvmi=>. Acesso em: 22 maio 2019.

GILE, D. Basic concepts and models for interpreter and translator training. Amsterdam/Philadelphia: John Benjamins Publishing, 2009.

González-Davies, M. A Collaborative Pedagogy for Translation. In: Venuti, L. (org.) Teaching Translation: Programs, Courses, Pedagogies. New York: Routledge, 2017. p. 71-78.

JIMÉNEZ-CRESPO, M. Á. Translation Crowndsourcing: Research Trends and Perspectives. In: CoRdingley, A.; MANnING, C. F. (org.) Collaborative Translation: From the Renaissance to the Digital Age. London/New York: Bloomsbury Publishing, 2017. p. 192-211.

KIRALY, D. C. From Assumptions about Knowing and Learning to Praxis in Translator Education. InTRAlinea. Special Issue: Challenges in Translation Pedagogy, 2014, pp. 1-9. Disponível em: <http://www.intralinea.org/print/article/2100>. Acesso em: 03 jan. 2019.

A Social Constructivist Approach to Translator Education: Empowerment from Theory to Practice. Manchester: St. Jerome, 2000.

Pathways to Translation: Pedagogy and Process. Kent, Ohio, EUA: Kent State University Press, 1995.

MCDONOUGH DolmaYA, J. The Ethics of Crowdsourcing. Linguistica Antverpiensia, $\mathrm{n}^{\circ}$ 10, 2011, pp. 97-111. Disponível em: <https://lans- 
tts.uantwerpen.be/index.php/LANS-TTS/article/view/279/177>. Acesso em: 22 maio 2019.

PItKÄSAlo, E.; Ketola, A. Collaborative Translation in a Virtual Classroom: Proposal for a Course Design. Transletters. International Journal of Translation and Interpreting, vol. 1, $\mathrm{n}^{\circ} 1$, 2018, pp. 93-119. Disponível em:

<https://www.uco.es/ucopress/ojs/index.php/tl/article/view/11035 >. Acesso em: 02 fev. 2019.

PYM, A. Translation Research Terms: A Tentative Glossary for Moments of Perplexity and Dispute. In: PYM, A. Translation Research Projects 3, Tarragona: Intercultural Studies Group, 2011: 75-110. Disponível em: <http://www.intercultural.urv.cat/media/upload/domain_317/arxius /TP3/isgbook3_web.pdf>. Acesso em: 03 mar. 2019.

Williams, J.; Chesterman, A. The Map: A Beginner's Guide to Doing Research in Translation Studies. Manchester: St. Jerome, 2002.

Wenger, E. Communities of practice: Learning as a social system. Systems Thinker, vol. 9, $\mathrm{n}^{\circ}$ 5, 1998, pp. 1-10. Disponível em: https://scholar.google.ca/scholar?hl=en\&as_sdt=0\%2C5\&q=Communit ies+of+practice\%3A+Learning+as+a+social+system\&btnG $=$. (22/05/2019).

Wolf, M.; FUKARI, A. (org.) Constructing a Sociology of Translation. Amsterdam/Philadelphia: John Benjamins, 2007.

Recebido em: 14/02/2019

Aceito em: 27/06/2019

Publicado em outubro de 2019 